\title{
Does the Porter formula hold its promise? A weight estimation formula for macrosomic fetuses put to the test
}

\author{
Christoph Weiss $^{1}$ (1) $\cdot$ Sabine Enengl ${ }^{1} \cdot$ Simon Hermann Enzelsberger ${ }^{1} \cdot$ Richard Bernhard Mayer $^{1} \cdot$ Peter Oppelt $^{1}$
}

Received: 21 April 2019 / Accepted: 7 December 2019 / Published online: 27 December 2019

(c) The Author(s) 2019

\begin{abstract}
Purpose Estimating fetal weight using ultrasound measurements is an essential task in obstetrics departments. Most of the commonly used weight estimation formulas underestimate fetal weight when the actual birthweight exceeds $4000 \mathrm{~g}$. Porter et al. published a specially designed formula in an attempt to improve detection rates for such macrosomic infants. In this study, we question the usefulness of the Porter formula in clinical practice and draw attention to some critical issues concerning the derivation of specialized formulas of this type.

Methods A retrospective cohort study was carried out, including 4654 singleton pregnancies with a birthweight $\geq 3500 \mathrm{~g}$, with ultrasound examinations performed within 14 days before delivery. Fetal weight estimations derived using the Porter and Hadlock formulas were compared.

Results Of the macrosomic infants, $27.08 \%$ were identified by the Hadlock formula, with a false-positive rate of $4.60 \%$. All macrosomic fetuses were detected using the Porter formula, with a false-positive rate of $100 \%$; $99.96 \%$ of all weight estimations using the Porter formula fell within a range of $4300 \mathrm{~g} \pm 10 \%$. The Porter formula only provides macrosomic estimates. Conclusions The Porter formula does not succeed in distinguishing macrosomic from normal-weight fetuses. High-risk fetuses with a birthweight $\geq 4500 \mathrm{~g}$ in particular are not detected more precisely than with the Hadlock formula. For these reasons, we believe that the Porter formula should not be used in clinical practice. Newly derived weight estimation formulas for macrosomic fetuses must not be based solely on a macrosomic data set.
\end{abstract}

Keywords Macrosomia $\cdot$ Ultrasonography $\cdot$ Fetal weight estimation $\cdot$ Formula $\cdot$ Porter $\cdot$ Hadlock

\section{Introduction}

An important task for obstetricians is to identify disproportionately heavy fetuses-known as macrosomic fetusesduring prenatal visits. Regrettably, the literature does not provide a consistent definition of macrosomia [1]. In general, fetuses with a birthweight (BW) $\geq 4000 \mathrm{~g}$ are considered macrosomic. Alternatively, the 95th or 97th percentile, or a $\mathrm{BW}$ of $\geq 4500 \mathrm{~g}$, is used for definition [2]. However,

Electronic supplementary material The online version of this article (https://doi.org/10.1007/s00404-019-05410-7) contains supplementary material, which is available to authorized users.

Christoph Weiss

Christoph.Weiss@kepleruniklinikum.at

1 Department of Gynecology, Obstetrics and Gynecological Endocrinology, Kepler University Hospital, Johannes Kepler University Linz, Altenberger Strasse 69, Krankenhausstrasse 26-30, 4040 Linz, Austria there is no doubt that there is a clear association between birth-related fetal injury (e.g., asphyxia or shoulder dystocia) and fetal BW [3-5]. In particular, fetuses weighing more than $4500 \mathrm{~g}$ are associated with a significantly increased risk of trauma $[1,6]$.

The greatest challenge in everyday practice is to detect macrosomic fetuses with sufficient certainty to provide suitable counseling for the expectant parents. Weight estimation formulas based on sonographic fetal measurements have long been in use for this purpose [7]. One of the internationally best-established sets of fetal weight estimation formulas is that by Hadlock et al., published in 1985 [8]. A major disadvantage of almost all formulas in use is undoubtedly that they underestimate the weight of macrosomic fetuses $[7,9]$. Over the years, a myriad of weight estimation formulas has been published in the hope of providing the obstetrician with a better tool for fetal weight estimation. Virtually, every measurable fetal variable has already been incorporated into this type of estimation formula, whether 
with two-dimensional [10] or three-dimensional [11, 12] measurements.

Some authors have argued that specialized formulas for certain weight ranges need to be developed to increase the accuracy of fetal weight estimation [13]. Porter et al. [14] dedicated themselves to the task and published a fetal weight estimation formula for macrosomic fetuses in 2015. They used standardized fetal measurements in a linear regression model to derive their formula. When comparing their new formula with the Hadlock formula, Porter et al. found that it provided a significantly higher detection rate for macrosomic fetuses in their study group.

The aim of the present study was to investigate and question the usefulness of the Porter formula in clinical practice in a large obstetric department for an unselected population. The study also draws attention to some critical issues concerning the derivation of this type of specialized formula and the potentially fatal consequences.

\section{Methods}

\section{Data collection}

This single-center retrospective cohort study included all births between January 1, 2013 and December 31, 2017 at the Department of Gynecology, Obstetrics, and Gynecological Endocrinology at Kepler University, Linz, Austria - the largest obstetrics ward in Austria, with around 3800 births per year. The data were obtained from our in-house computer database of perinatal records.

The inclusion criteria were: singleton pregnancy, liveborn infants with a $\mathrm{BW} \geq 3500 \mathrm{~g}$, a complete data set of ultrasound examinations, and-based on the inclusion criteria described by Porter et al. [14]—fetal measurements that had been performed within 14 days before delivery. Only the most recent estimated fetal weight (EFW) was taken into account. The data represent an unselected cross section of the population.

A cut-off value of $3500 \mathrm{~g}$ was selected for two reasons: first, the Porter formula was specifically designed to detect macrosomic fetuses when "macrosomia is suspected." All fetuses in this analysis that had a birthweight well into the normal range were, therefore, excluded. Second, commonly used 2D fetal weight estimation formulas are relatively accurate up to $3500 \mathrm{~g}$ [15].

Ultrasound examinations form part of routine prenatal management in the department. The examinations were performed transabdominally by experienced physicians, using high-quality ultrasound systems (Voluson E6 and E8, GE Medical Systems, Zipf, Austria). Women with a normal pregnancy history visit the department for the first time at around $37+0$ weeks of gestation. A final routine weight estimation is performed at term. In our department, induction of labor is recommended at 40 gestational weeks plus 10 days.

Routine weight estimation included measurements of the biparietal diameter (BPD), head circumference (HC), abdominal circumference (AC), and femur length (FL) in accordance with the International Society of Ultrasound in Obstetrics and Gynecology (ISUOG) recommendations [16]. The Hadlock formula using all four fetal parameters (BPD, HC, AC, and FL) [8] is used for weight estimation in our department and was used in this study.

Gestational age was assessed relative to the crown-rump length measured at the first-trimester ultrasound examination. These measurements were made by physicians in private practice during the mandatory maternal examination. If the crown-rump length was not known, the first day of the last menstrual period was used for gestational age assessment. Delivery data such as BW and sex were filed by midwives in a separate database.

For this study, the EFW provided by the Hadlock formula was compared with the EFW determined by the Porter formula using the same fetal measurements.

\section{Ethical approval}

In accordance with the guidelines, and with confirmation in a written statement by the chairman of the Research Ethics Committee of Upper Austria, no specific ethical approval was necessary for this retrospective study. A waiver of consent was approved.

\section{Statistics}

The accuracy of the two formulas for predicting fetal macrosomia (defined as BW $\geq 4000 \mathrm{~g}$ ) was tested using absolute error: (IEFW $-\mathrm{BWI}$ ), percentage error: $(\mathrm{EFW}-\mathrm{BW} /$ $\mathrm{BW} \times 100)$, absolute percentage error: $(\mathrm{IEFW}-\mathrm{BWI}$ $\mathrm{BW} \times 100$ ), sensitivity, specificity, false-positive rate, false-negative rate, positive predictive value, negative predictive value, and overall accuracy defined as (truepositive plus true-negative)/all cases.

Percentages of EFWs falling within the $\pm 5 \%$ and $\pm 10 \%$ ranges of the actual BW were calculated for both formulas.

On the basis of the findings reported by Faschingbauer et al. [17], a subgroup analysis of all births in the study group within a scan-to-delivery interval of 3 days was performed. Statistical analysis was carried out using the $\mathrm{R}$ statistical software package [18]. For numerical variables, $t$ tests were carried out. For all analyses, $P<0.05$ was considered statistically significant. 
Table 1 Demographic and clinical parameters in the study population $(n=4654)$, given as means $( \pm \operatorname{SD})$

\begin{tabular}{ll}
\hline Maternal age (years) & $30.43( \pm 5.2)$ \\
Gestational age at delivery (days) & $280.59( \pm 7.3)$ \\
Time from fetal weight estimation to delivery & $6.00( \pm 3.9)$ \\
$\quad$ (days) & $3840.25( \pm 268.4)$ \\
Birth weight $(\mathrm{g})$ & $2741 / 1913$ \\
Gender (male/female) & \\
\hline
\end{tabular}

Table 2 Classification parameters for macrosomia with each formula

\begin{tabular}{lll}
\hline & Hadlock $(\%)$ & Porter $(\%)$ \\
\hline Sensitivity & 27.08 & 100 \\
Specificity & 95.40 & 0 \\
PPV & 66.03 & 24.83 \\
NPV & 79.83 & 0 \\
FNR & 72.92 & 0 \\
FPR & 4.60 & 100 \\
Overall accuracy & 78.43 & 24.83 \\
\hline
\end{tabular}

$F N R$ false-negative rate, $F P R$ false-positive rate, $N P V$ negative predictive value, $P P V$ positive predictive value

\section{Results}

A total of 4654 births met the inclusion criteria; 1156 infants (24.84\%) had a BW $\geq 4000 \mathrm{~g}, 110(2.36 \%)$ weighed $\geq 4500 \mathrm{~g}$, and only seven infants weighed more than $5000 \mathrm{~g}$. Table 1 lists the demographic and obstetric characteristics of the study group.

Among the macrosomic infants ( $\mathrm{BW} \geq 4000 \mathrm{~g}$ ), 313 (27.08\%) were identified using the Hadlock formula, with a false-positive rate of $4.60 \%$. In contrast, all macrosomic fetuses were detected using the Porter formula, with a false-positive rate of $100 \%$. Ten $(9 \%)$ of the infants weighing more than $4500 \mathrm{~g}$ were correctly detected with the Hadlock formula, the same number as with the Porter formula. None of the infants weighing $\geq 5000 \mathrm{~g}$ was detected by either formula. The mean time interval between measurement and birth in infants $\geq 4000 \mathrm{~g}$ was 5.8 days $( \pm \mathrm{SD}$ 4.0 days). In general, the mean interval between ultrasound examination and birth was 6.0 days ( \pm SD 3.9 days, $P=0.18$ ).

The individual classification parameters for each formula are summarized in Table 2. Table 3 shows the mean percentage error, mean absolute percentage error, and mean absolute error for both formulas.

The overall percentages of weight estimates falling within $\pm 5 \%$ and $\pm 10 \%$ of the BW using the Hadlock formula were $33.15 \%$ and $64.42 \%$, respectively; the corresponding figures for the Porter formula were $15.58 \%$ and $38.09 \%$. For macrosomic infants, $22.66 \%$ of the Hadlock estimates and $63.67 \%$ of the Porter estimates were within $\pm 5 \%$ of the BW; $51.99 \%$ (Hadlock) and $97.75 \%$ (Porter) were within $\pm 10 \%$. In other words, in the study group as a whole, $99.44 \%$ of all weight estimations using the Porter formula were within a range of $4300 \mathrm{~g} \pm 5 \%$. and $99.96 \%$ were within a range of $4300 \mathrm{~g} \pm 10 \%$, with a mean estimated weight of $4263 \mathrm{~g}(\mathrm{SD} \pm 56.78 \mathrm{~g})$ (Fig.1).

In the subgroup analysis including only births of macrosomic fetuses with a weight estimation within 3 days of delivery $(n=1388)$, the Hadlock formula showed improved sensitivity in comparison with the whole-study group $-50.25 \%$ and $27.08 \%$, respectively. However, the Porter formula did not show any improved performance. Table 4 lists the demographic and obstetric characteristics in this subgroup. The classification parameters are summarized in Table 5.
Table 3 Mean percentage error, mean absolute percentage error, and mean absolute error values derived from the Hadlock and Porter formulas for all births in the study group and classified into birth weights $<4000 \mathrm{~g}$ and $\geq 4000 \mathrm{~g}$

\begin{tabular}{lccc}
\hline & Hadlock & Porter & $P$ value \\
\hline BW $\geq 3500 \mathrm{~g}(n=4654)$ & & & $<0.0001$ \\
Mean PE $( \pm$ SD $)$ & $-6.78 \%( \pm 7.7 \%)$ & $11.51 \%( \pm 7.0 \%)$ & $<0.0001$ \\
Mean APE $( \pm$ SD $)$ & $8.42 \%( \pm 5.8 \%)$ & $12.03 \%( \pm 6.1 \%)$ & $<0.0001$ \\
Mean AE $( \pm$ SD & $327.15 \mathrm{~g}( \pm 236.6 \mathrm{~g})$ & $447.58 \mathrm{~g}( \pm 209.5 \mathrm{~g})$ & \\
BW $<4000 \mathrm{~g}(n=3498)$ & & & $<0.0001$ \\
Mean PE $( \pm$ SD $)$ & $-5.95( \pm 7.5 \%)$ & $14.65 \%( \pm 4.4 \%)$ & $<0.0001$ \\
Mean APE $( \pm$ SD $)$ & $7.82( \pm 5.5 \%)$ & $14.65 \%( \pm 4.4 \%)$ & $<0.0001$ \\
Mean AE $( \pm$ SD $)$ & $291.28 \mathrm{~g}( \pm 196.7 \mathrm{~g})$ & $538.41 \mathrm{~g}( \pm 143.8 \mathrm{~g})$ & $<0.0001$ \\
BW $\geq 4000 \mathrm{~g}(n=1156)$ & & & $<0.0001$ \\
Mean PE $( \pm \mathrm{SD})$ & $-9.32 \%( \pm 7.8 \%)$ & $2.01 \%( \pm 4.4 \%)$ & $<0.0001$ \\
Mean APE $( \pm \mathrm{SD})$ & $10.26 \%( \pm 6.5 \%)$ & $4.09 \%( \pm 2.6 \%)$ & $172.72 \mathrm{~g}( \pm 116.2 \mathrm{~g})$ \\
Mean AE $( \pm \mathrm{SD})$ & $435.72 \mathrm{~g}( \pm 284.4 \mathrm{~g})$ & & \\
\hline
\end{tabular}

$A E$ absolute error, $A P E$ absolute percentage error, $B W$ birth weight, $P E$ percentage error 


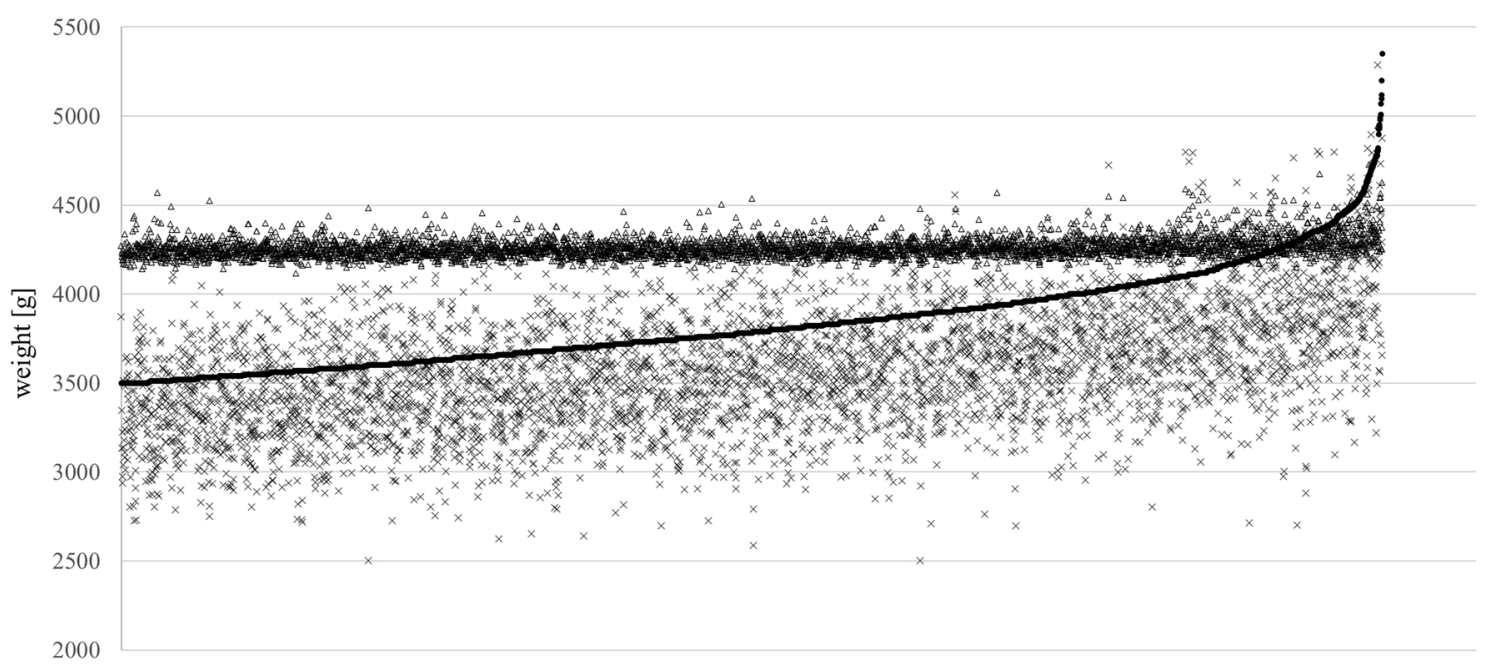

study group ranked by birthweight

Fig. 1 Scatter plot of all births $(n=4654)$, ranked by increasing birthweight (BW). In all, $313(27.08 \%)$ of the macrosomic infants $(\mathrm{BW} \geq 4000 \mathrm{~g}$ ) were correctly identified using the Hadlock formula; $1156(100 \%)$ were detected using the Porter formula. The favorable appearance is achieved by the fact that the Porter formula sets the estimated weights within a very narrow band at around $4300 \mathrm{~g}$;

Table 4 Demographic and clinical parameters for the subgroup analysis, including only births with a fetal weight estimation $\leq 3$ days before delivery $(n=1388)$, given as means $( \pm$ SD)

\begin{tabular}{ll}
\hline Maternal age (years) & $30.34( \pm 5.3)$ \\
Gestational age at delivery (days) & $279.21( \pm 7.2)$ \\
Time from fetal weight estimation to delivery & $1.44( \pm 0.8)$ \\
$\quad$ (days) & \\
Birth weight $(\mathrm{g})$ & $3863.27( \pm 281.0)$ \\
Gender (male/female) & $802 / 586$ \\
\hline
\end{tabular}

Table 5 Classification parameters for macrosomia with each formula in the subgroup analysis, including only births with a fetal weight estimation $\leq 3$ days before delivery $(n=1388)$

\begin{tabular}{lll}
\hline & Hadlock $(\%)$ & Porter $(\%)$ \\
\hline Sensitivity & 50.25 & 100 \\
Specificity & 88.65 & 0 \\
PPV & 63.55 & 28.24 \\
NPV & 81.91 & 0 \\
FNR & 49.74 & 0 \\
FPR & 11.35 & 100 \\
Overall accuracy & 77.81 & 28.24 \\
\hline
\end{tabular}

$F N R$ false-negative rate, FPR false-positive rate, $N P V$ negative predictive value, $P P V$ positive predictive value
99.44\% of all weight estimations using the Porter formula were within a range of $4300 \mathrm{~g} \pm 5 \%$, leading to massive overestimation of normal-weight fetuses. •, Actual birthweight; $\Delta$, fetal weight estimated with the Porter formula; $x$, fetal weight estimated with the Hadlock formula

\section{Discussion}

Although a vast number of weight estimation formulas for macrosomic fetuses have been published in the past, many more will undoubtedly follow. This is not surprising, as we are still failing to detect macrosomic fetuses with satisfactory accuracy. Obstetricians worldwide are still using weight estimation formulas developed in the 1980s, such as the Hadlock formulas, or those of Merz [19] and Shepard [20], published in 1988 and 1982, respectively. Those formulas, which were never intended specifically for large fetuses but rather represent "all-rounder" formulas, notoriously underestimate the weight of macrosomic fetuses [7, 9]. They all fail to detect such at-risk fetuses with sufficient certainty. Nevertheless, the Hadlock formulas still show favorable results in comparison with others [21].

Porter et al. [14] stated that they were able to diagnose macrosomic fetuses significantly better with their new formula than with the well-established Hadlock formula. Superficially, the figures they present seem to be convincing. However, if one takes a closer look at the "behavior" of the Porter formula, one quickly realizes that the apparently good hit ratio for fetuses with a $\mathrm{BW} \geq 4000 \mathrm{~g}$ is achieved, only because the Porter formula puts virtually all weight estimates within a very narrow band around $4300 \mathrm{~g}$. This behavior is best explained by the selection criteria used for the formula-finding group. The formula is based on a training data set $(n=201)$ including only fetuses with a $\mathrm{BW} \geq 4000 \mathrm{~g}$. If this formula is tested with a data set that similarly includes only fetuses with 
a BW $\geq 4000$ g, naturally excellent results are produced. The mean BW for their whole-study group was $4236 \mathrm{~g}$. Moreover, Porter et al. included the data set of the formula-finding group in the comparison between their new formula and the Hadlock formula. This procedure appears at least questionable. They never applied their formula to fetuses with a BW below $4000 \mathrm{~g}$.

With this mode of derivation, such a formula will never succeed in distinguishing macrosomic fetuses from normalweight ones. It will always deliver a macrosomic fetal weight estimation. Bluntly put, no matter what measurements you enter, the Porter formula always delivers a value of around $4300 \mathrm{~g}$. This also applies to children with a BW well below $3500 \mathrm{~g}$. In fetuses with a BW between $1014 \mathrm{~g}$ and $5350 \mathrm{~g}$, the lowest weight estimate produced by the Porter formula was $4105 \mathrm{~g}$ (see supplementary data).

Furthermore, Porter et al. [14] did not define any rules or cut-off values for when their formula should be applied. They only vaguely stated that the formula "should be considered when macrosomia is suspected." Used in this way, the Porter formula will always confirm such a suspicion, even when the real fetal weight is far below $4000 \mathrm{~g}$ (see supplementary data).

This has serious clinical consequences. On one hand, normal-weight fetuses are massively overestimated, and on the other hand, fetuses with the highest birth risk (BW $>4500 \mathrm{~g}$ ) will not be detected. The same problem applies to the formula for macrosomic fetuses published by Hart et al. in 2010 $[22,23]$.

If such formulas were to be implemented in everyday clinical practice, their unreliable results would lead to completely unnecessary uncertainty on the part of expectant mothers and obstetricians alike. Many women with normalweight fetuses would unnecessarily be classified as having pathological findings. Using the Porter formula, virtually, all pregnant women would be diagnosed as having macrosomic fetuses.

Faschingbauer et al. [17] showed that the optimal scan-todelivery interval for detecting macrosomic fetuses is 3 days. Even when these findings are taken into account, the Porter formula does not show better parameters.

It has been shown previously that labor abnormalities such as arrested labor are more likely to be diagnosed when fetal macrosomia is suspected despite the real BW [24, 25]. The same applies to cesarean delivery rates. Melamed et al. showed that cesarean delivery rates increase by up to 2.5 times when the fetal weight estimate is $\geq 4000 \mathrm{~g}$ regardless of the actual BW [26]. Just recently, similar results were published by Vitner et al., showing an increase even up to 3.5 times [27]. Blackwell et al. calculated that overestimation of fetal weight on ultrasound lowers the threshold for cesarean delivery for labor arrest even when the EFW is $<4000 \mathrm{~g}$ [28].
Predicted fetal macrosomia is also associated with a higher rate of labor induction [27, 29], even though there are no recommendations on this topic. On the contrary, several authors have argued that suspected macrosomia alone does not justify induction of labor or primary cesarean delivery [30-32]. The American College of Obstetricians and Gynecologists (ACOG) clearly states that suspected fetal macrosomia is not an indication for inducing labor [33].

In the past, virtually every measurable fetal and/or maternal variable has been used for formula derivation by linear regression. Alas, no particular formula emerged showing a sufficient accuracy in detecting macrosomic fetuses. Thus, the authors of this study strongly believe that no additional fetal weight estimation formulas derived by linear regression are needed. As Kehl et al. already stated in 2012 [34], "weight estimation with conventional biometric parameters by $2 \mathrm{D}$ ultrasound has reached its limits". To use the existing formulas more effectively, some authors have favored a "two-step procedure" for fetal weight estimation [35]. In such an approach, in a first step, the weight range is delineated by one or more sonographic parameters (e.g., AC). Depending on the results, in a second step, fetal weight is estimated by a formula selected by defined thresholds [36, 37]. Whether such an approach enables the obstetrician in clinical practice to improve fetal and/or maternal outcome still has to be shown through clinical trials. Because, not everything that appears to be significant in a published report proves to be of clinical relevance. Perhaps using completely new approaches, e.g., machine learning algorithms, we will succeed in detecting fetuses at risk with sufficient accuracy [38]. The future will tell.

For the present, a macrosomic fetus in utero will continue to present a diagnostic dilemma. All too easily, today's highly sophisticated ultrasound equipment may lead to the misjudgment that we are able to estimate fetal weight better than is actually the case. The current ACOG Practice Bulletin reflects this by stating rather mischievously that "an accurate diagnosis of macrosomia can only be made by weighing the newborn after delivery" [33].

\section{Strengths and limitations of the study}

The retrospective character and the single-center setting in this study can certainly be regarded as limiting factors. In our opinion, these weaknesses are compensated for by the size of the study group. It might be argued that including fetal measurements up to 14 days before delivery might lead to further distortion of the fetal weight estimates. As stated above, this time interval was chosen on the basis of the inclusion criteria used by Porter et al. [14]. In any case, the mean interval between ultrasound examinations and birth was 6 days for the whole-study group. In our opinion, this resembles a real-life situation. 
We were not able to provide demographic parameters concerning preexisting diabetes mellitus, gestational diabetes, or the women's body mass index. This is because we would have had to obtain such data by a manual review of all clinical reports.

\section{Conclusion}

In our opinion, the Porter formula does not offer any clinical benefit in detecting macrosomic fetuses. Using the Porter formula results in a massive overestimation of normalweight fetuses. This would lead to an unnecessary increase in rates of labor induction and cesarean sections. Furthermore, high-risk fetuses with a $\mathrm{BW} \geq 4500 \mathrm{~g}$ in particular are not detected more precisely than with the Hadlock formula. For these reasons, we believe that the Porter formula should not be used in clinical practice.

Newly derived weight estimation formulas for macrosomic fetuses must not be based solely on a macrosomic data set. If they are, such a formula will never be capable of distinguishing between macrosomic and normal-weight fetuses.

Acknowledgements Open access funding provided by Johannes Kepler University Linz.

Authors' contributions $\mathrm{CW}$ : project development, data collection, and manuscript writing. SE: data collection. SHE: data collection. RBM: manuscript writing. PO: manuscript editing.

\section{Compliance with ethical standards}

Conflict of interest The authors declare that they have no conflicts of interest.

Open Access This article is licensed under a Creative Commons Attribution 4.0 International License, which permits use, sharing, adaptation, distribution and reproduction in any medium or format, as long as you give appropriate credit to the original author(s) and the source, provide a link to the Creative Commons licence, and indicate if changes were made. The images or other third party material in this article are included in the article's Creative Commons licence, unless indicated otherwise in a credit line to the material. If material is not included in the article's Creative Commons licence and your intended use is not permitted by statutory regulation or exceeds the permitted use, you will need to obtain permission directly from the copyright holder. To view a copy of this licence, visit http://creativecommons.org/licenses/by/4.0/.

\section{References}

1. Campbell S (2014) Fetal macrosomia: a problem in need of a policy. Ultrasound Obstet Gynecol 43(1):3-10
2. Ye J, Zhang L, Chen Y, Fang F, Luo Z, Zhang J (2014) Searching for the definition of macrosomia through an outcome-based approach. PLoS ONE 9:e100192

3. Spellacy WN, Miller S, Winegar A, Peterson PQ (1985) Macrosomia-maternal characteristics and infant complications. Obstet Gynecol 66(2):158-161

4. Gudmundsson S, Henningsson A-C, Lindqvist P (2005) Correlation of birth injury with maternal height and birthweight. BJOG Int J Obstet Gynaecol 112(6):764-767

5. Jolly MC, Sebire NJ, Harris JP, Regan L, Robinson S (2003) Risk factors for macrosomia and its clinical consequences: a study of 350,311 pregnancies. Eur J Obstet Gynecol Reprod Biol 111(1):9-14

6. Boulet SL, Alexander GR, Salihu HM, Pass M (2003) Macrosomic births in the United States: determinants, outcomes, and proposed grades of risk. Am J Obstet Gynecol 188(5):1372-1378

7. Dudley NJ (2005) A systematic review of the ultrasound estimation of fetal weight. Ultrasound Obstet Gynecol 25(1):80-89

8. Hadlock FP, Harrist RB, Sharman RS, Deter RL, Park SK (1985) Estimation of fetal weight with the use of head, body, and femur measurements-a prospective study. Am J Obstet Gynecol 151(3):333-337

9. Hoopmann M, Abele H, Wagner N, Wallwiener D, Kagan KO (2010) Performance of 36 different weight estimation formulae in fetuses with macrosomia. Fetal Diagn Ther 27(4):204-213

10. Dudley NJ, Lamb MP, Copping C (1987) A new method for fetal weight estimation using real-time ultrasound. Br J Obstet Gynaecol 94(2):110-114

11. Yang F, Leung KY, Hou YW, Yuan Y, Tang MH (2011) Birthweight prediction using three-dimensional sonographic fractional thigh volume at term in a Chinese population. Ultrasound Obstet Gynecol 38(4):425-433

12. Schild RL, Fimmers R, Hansmann M (2000) Fetal weight estimation by three-dimensional ultrasound. Ultrasound Obstet Gynecol 16(5):445-452

13. Souka AP, Papastefanou I, Michalitsi V, Pilalis A, Kassanos D (2014) Specific formulas improve the estimation of fetal weight by ultrasound scan. J Matern Fetal Neonatal Med 27(7):737-742

14. Porter B, Neely C, Szychowski J, Owen J (2015) Ultrasonographic fetal weight estimation: should macrosomia-specific formulas be utilized? Am J Perinatol 32(10):968-972

15. Scioscia M, Vimercati A, Ceci O, Vicino M, Selvaggi LE (2008) Estimation of birth weight by two-dimensional ultrasonography: a critical appraisal of its accuracy. Obstet Gynecol 111(1):57-65

16. Salomon LJ, Alfirevic Z, Berghella V, Bilardo C, HernandezAndrade E, Johnsen SL et al (2011) Practice guidelines for performance of the routine mid-trimester fetal ultrasound scan. Ultrasound Obstet Gynecol 37(1):116-126

17. Faschingbauer F, Dammer U, Raabe E, Schneider M, Faschingbauer C, Schmid M (2015) Sonographic weight estimation in fetal macrosomia: influence of the time interval between estimation and delivery. Arch Gynecol Obstet 292(1):59-67

18. Development Core Team R (2011) R: a language and environment for statistical computing. R Foundation for Statistical Computing, Vienna

19. Merz E, Lieser H, Schicketanz KH, Härle J (1988) Intrauterine fetal weight assessment using ultrasound A comparison of several weight assessment methods and development of a new formula for the determination of fetal weight. Ultraschall Med 9(1):15-24

20. Shepard MJ, Richards VA, Berkowitz RL, Warsof SL, Hobbins JC (1982) An evaluation of two equations for predicting fetal weight by ultrasound. Am J Obstet Gynecol 142(1):47-54

21. Aviram A, Yogev Y, Ashwal E, Hiersch L, Hadar E, GabbayBenziv R (2017) Prediction of large for gestational age by 
various sonographic fetal weight estimation formulas-which should we use? J Perinatol 37(5):513-517

22. Hart NC, Hilbert A, Meurer B, Schrauder M, Schmid M, Siemer J, Voigt M, Schild RL (2010) Macrosomia: a new formula for optimized fetal weight estimation. Ultrasound Obstet Gynecol 35(1):42-47

23. Weiss C, Oppelt P, Mayer RB (2018) Disadvantages of a weight estimation formula for macrosomic fetuses: the Hart formula from a clinical perspective. Arch Gynecol Obstet 298(6):1101-1106

24. Weeks JW, Pitman T, Spinnato JA (1995) Fetal macrosomia: does antenatal prediction affect delivery route and birth outcome? Am J Obstet Gynecol 173(4):1215-1219

25. Levine AB, Lockwood CJ, Brown B, Lapinski R, Berkowitz RL (1992) Sonographic diagnosis of the large for gestational age fetus at term: does it make a difference? Obstet Gynecol 79(1):55-58

26. Melamed N, Yogev Y, Meizner I, Mashiach R, Ben-Harousch A (2010) Sonographic prediction of fetal macrosomia: the consequences of false diagnosis. J Ultrasound Med 29(2):225-230

27. Vitner D, Bleicher I, Kadour-Peero E, Lipworth H, Sagi S, Gonen R (2019) Does prenatal identification of fetal macrosomia change management and outcome? Arch Gynecol Obstet 299(3):635-644

28. Blackwell SC, Refuerzo J, Chadha R, Carreno CA (2009) Overestimation of fetal weight by ultrasound: does it influence the likelihood of cesarean delivery for labor arrest? Am J Obstet Gynecol 200(3):340.e1-340.e3

29. Sadeh-Mestechkin D, Walfisch A, Shachar R, Shoham-Vardi I, Vardi H, Hallak M (2008) Suspected macrosomia? Better not tell. Arch Gynecol Obstet 278(3):225-230

30. Chauhan SP, Grobman WA, Gherman RA, Chauhan VB, Chang G, Magann EF, Hendrix NW (2005) Suspicion and treatment of the macrosomic fetus: a review. Am J Obstet Gynecol 193(2):332-346

31. Sanchez-Ramos L, Bernstein S, Kaunitz AM (2002) Expectant management versus labor induction for suspected fetal macrosomia: a systematic review. Obstet Gynecol 100(5 Pt 1):997-1002
32. Gonen R, Bader D, Ajami M (2000) Effects of a policy of elective cesarean delivery in cases of suspected fetal macrosomia on the incidence of brachial plexus injury and the rate of cesarean delivery. Am J Obstet Gynecol 183(5):1296-1300

33. American College of Obstetricians and Gynecologists' Committee on Practice Bulletins-Obstetrics (2016) Practice Bulletin No. 173: Fetal Macrosomia. Obstet Gynecol 128(5):e195-e209

34. Kehl S, Schmidt U, Spaich S, Schild RL, Sütterlin M, Siemer J (2012) What are the limits of accuracy in fetal weight estimation with conventional biometry in two-dimensional ultrasound? A novel postpartum study. Ultrasound Obstet Gynecol 39:543-548

35. Hoopmann M, Kagan KO, Sauter A, Abele H, Wagner P (2016) Comparison of errors of 35 weight estimation formulae in a standard collective. Geburtshilfe Frauenheilkd 76(11):1172-1179

36. Kehl S, Koerber C, Hart N, Goecke TW, Schild RL, Siemer J (2012) New sonographic method for fetuses with a large abdominal circumference improves fetal weight estimation. Ultraschall Med 33:265-269

37. Balsyte D, Schäffer L, Zimmermann R, Kurmanavicius J, Burkhardt T (2017) Optimized sonographic weight estimation of fetuses over $3500 \mathrm{~g}$ using biometry-guided formula selection. Ultraschall Med 38(1):60-64

38. Tsur A, Batsry L, Toussia-Cohen S, Rosenstein MG, Barak O, Brezinov Y, Yoeli-Ullman R, Sivan E, Sirota M, Druzin ML, Stevenson DK, Blumenfeld YJ, Aran D (2019) Development and validation of a machine learning model for prediction of shoulder dystocia. Ultrasound Obstet Gynecol. https://doi.org/10.1002/ uog. 21878

Publisher's Note Springer Nature remains neutral with regard to jurisdictional claims in published maps and institutional affiliations. 